\title{
XAS Characterization of a Nitridoiron(IV) Complex with a Very Short Fe-N Bond
}

\author{
Jan-Uwe Rohde $†, \ddagger$, Theodore A. Betley§,\|, Timothy A. Jackson†, Caroline T. Saouma $§$, \\ Jonas C. Peters $\S$, and Lawrence Que Jr. $†$ \\ Department of Chemistry and Center for Metals in Biocatalysis, 207 Pleasant St. S.E., University of \\ Minnesota, Minneapolis, Minnesota 55455, U.S.A. and Department of Chemistry and Chemical \\ Engineering, Arnold and Mabel Beckman Laboratories of Chemical Synthesis, California Institute \\ of Technology, Pasadena, California 91125, U.S.A
}

\begin{abstract}
X-ray absorption spectroscopy has been used to characterize the novel nitridoiron(IV) unit in $\left[\mathrm{PhBP}^{i \mathrm{Pr}}{ }_{3}\right] \mathrm{Fe}(\mathrm{N})$ and obtain direct spectroscopic evidence for a very short $\mathrm{Fe}-\mathrm{N}$ distance. The distance of 1.52(2) $\AA$ reflects the presence of an $\mathrm{Fe} \equiv \mathrm{N}$ triple bond in accord with the observed $\mathrm{Fe} \equiv \mathrm{N}$ vibration $\left(v_{\mathrm{FeN}}=1034 \mathrm{~cm}^{-1}\right)$. This highly covalent bonding interaction results in the appearance of an unusually intense pre-edge peak, whose estimated area of 100(20) units is much larger than those of the related tetrahedral complexes with $\mathrm{Fe}^{\mathrm{I}}-\mathrm{N}_{2}-\mathrm{Fe}^{\mathrm{I}}, \mathrm{Fe}^{\mathrm{II}}-\mathrm{NPh}_{2}$, and $\mathrm{Fe}{ }^{\mathrm{III}} \equiv \mathrm{NAd}$ motifs, and those of recently described six-coordinate $\mathrm{Fe}^{\mathrm{V}} \equiv \mathrm{N}$ and $\mathrm{Fe}{ }^{\mathrm{VI}} \equiv \mathrm{N}$ complexes. The observation that the $\mathrm{Fe} \mathrm{IV}_{-}$ $\mathrm{N}$ distance of $\left[\mathrm{PhBP}^{i \mathrm{Pr}}{ }_{3}\right] \mathrm{Fe}(\mathrm{N})$ is shorter than the $\mathrm{Fe}^{\mathrm{IV}}-\mathrm{O}$ bond lengths of oxoiron(IV) complexes may be rationalized on the basis of the greater $\pi$ basicity of the nitrido ligand than the oxo ligand and a lower metal coordination number for the $\mathrm{Fe}(\mathrm{N})$ complex.
\end{abstract}

There has been much recent interest in the preparation and characterization of iron complexes that feature metal-to-ligand multiple bonds, 1,2 with oxo, imido, and nitrido functionalities being most noteworthy in this regard. Metrical parameters for species of these types are of much interest as they can be correlated with their electronic structures and reactivity patterns. Knowledge in this area contributes to our general understanding of the roles such iron species can play in biocatalysis ${ }^{3-5}$ and synthetic and catalytic atom and group transfer reactions. 1,6 , 7 Until very recently, well-characterized mononuclear $\mathrm{Fe}(\mathrm{NR})$ and $\mathrm{Fe}(\mathrm{N})$ complexes were virtually unknown, but at this stage there are examples of these types of compounds spanning the entire range of oxidation states from $\mathrm{Fe}^{\mathrm{II}}$ to $\mathrm{Fe}^{\mathrm{VI} .8-15}$

More specifically, Wieghardt and coworkers have recently characterized two fascinating sixcoordinate iron nitrido complexes in the $+\mathrm{V}$ and $+\mathrm{VI}$ oxidation states using a suite of spectroscopic techniques. ${ }^{14,15}$ Their effort follows earlier work by Nakamoto in which the generation of an $\mathrm{Fe}^{\mathrm{V}}$ nitride at low temperature was postulated based upon resonance Raman data in conjunction with elegant labeling studies. ${ }^{16}$ On the other hand, the Peters group has reported on the generation of a structurally distinct family of pseudotetrahedral $\mathrm{Fe} \equiv \mathrm{N}_{\mathrm{X}}$ species. This family of complexes has included two $\mathrm{Fe}^{\mathrm{IV}}$ nitrido species, ${ }_{13}, 17$ in addition to iron imides in each of the oxidation states $+\mathrm{II},{ }^{9}+\mathrm{III},{ }^{10-12,18}$ and +IV. ${ }^{12}$ The pseudotetrahedral $\mathrm{L}_{3} \mathrm{Fe} \equiv \mathrm{N}_{\mathrm{X}}$ species are stabilized by tris(phosphino)borate (generically abbreviated as $\left[\mathrm{PhBP}_{3}{ }_{3}\right]^{-}$) and pyrazolylbis(phosphino)borate ligands and feature strong covalent bonding

\footnotetext{
$\dagger$ University of Minnesota.

\$Current address: Department of Chemistry, The University of Iowa, Iowa City, IA 52242

$\S$ California Institute of Technology.

ICurrent address: Department of Chemistry, Massachusetts Institute of Technology, Cambridge, MA 02139.
} 
characterized by $\mathrm{Fe} \equiv \mathrm{N}_{\mathrm{x}}$ triple bonds. Metrical parameters have been readily obtained for imidoiron species with +II, +III, and +IV oxidation states from low temperature X-ray crystallography. It has been found that the $F e-N \mathrm{R}$ bond length in these imides is virtually insensitive to the oxidation state of the metal center; in all cases it is ca. 1.65(2) $\AA$. This observation is consistent with the triple bond description that has been forwarded. $2,9,12$ Unfortunately, the $\mathrm{Fe}-\mathrm{N}$ distances of the nitridoiron(IV) complexes have not been determined crystallographically. In the case of $\left[\mathrm{PhBP}^{i{ }^{i r}}{ }_{3}\right] \mathrm{Fe}^{\mathrm{IV}} \equiv \mathrm{N}$, the high concentrations typically needed for crystallization result in the dimerization of the complex to afford the diiron(I) $\mathrm{N}_{2}$-bridged product $\left\{\left[\mathrm{PhBP}^{i \mathrm{Pr}}{ }_{3}\right] \mathrm{Fe}\right\}_{2}\left(\mu-\mathrm{N}_{2}\right) .{ }^{13}$ Since the $\mathrm{Fe}^{\mathrm{IV}} \equiv \mathrm{N}$ bond length is a critical parameter to ascertain, especially for direct comparison with octahedrally coordinated nitrido, imido, and oxo species of high valent iron, we have turned to Fe K-edge X-ray absorption spectroscopy (XAS) and the analysis of the extended X-ray absorption fine structure (EXAFS) as a means to obtain such information. Herein we provide XAS data that serve to characterize the series

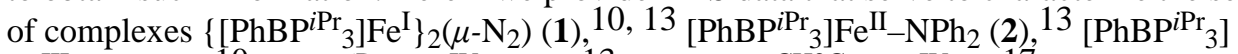
$\mathrm{Fe}^{\mathrm{III}} \equiv \mathrm{NAd}(\mathbf{3}),{ }^{10}\left[\mathrm{PhBP}^{i \mathrm{Pr}}{ }_{3}\right] \mathrm{Fe}^{\mathrm{IV}} \equiv \mathrm{N}(\mathbf{4}),{ }^{13}$ and $\left[\mathrm{PhBP}^{\mathrm{CH} 2 \mathrm{Cy}}{ }_{3}\right] \mathrm{Fe}^{\mathrm{IV}} \equiv \mathrm{N} .17$

\section{Experimental Section}

\section{Sample Preparation}

Complexes $\mathbf{1}$ - $\mathbf{5}$ were prepared as described previously. ${ }^{10,13,17} \mathrm{X}$-ray absorption spectra of $\mathbf{1}-\mathbf{3}$ were obtained on solid samples prepared by grinding the iron complex $(1 \mathrm{mg})$ and boron nitride $(99 \mathrm{mg})$ into a homogeneous mixture under an inert gas atmosphere. A total of $20 \mathrm{mg}$ of the solid mixture was then packed into a sample plate $(1 \mathrm{~mm}$ thickness) and covered with Mylar tape. Samples of 4 were prepared in benzene- $d_{6}$ or toluene- $d_{8}$ solution by the following protocol: Complex $\mathbf{4}$ was generated by the addition of a thawing solution of $\left[\mathrm{PhBP}^{i \mathrm{Pr}}{ }_{3}\right] \mathrm{FeCl}$ in THF (ca. $-110{ }^{\circ} \mathrm{C}$ ) to solid $\mathrm{Li}$-2,3:5,6-dibenzo-7-aza bicyclo[2.2.1] hepta-2,5-diene (dbabh). The solution was incubated at room temperature for 15 min during which anthracene was released and $\mathbf{4}$ was produced. Three samples of $\mathbf{4}$ were independently prepared: a $0.01 \mathrm{M}$ solution in $\mathrm{C}_{6} \mathrm{D}_{6}(\mathbf{4 A})$, a $0.03 \mathrm{M}$ solution in $\mathrm{C}_{7} \mathrm{D}_{8}(\mathbf{4 B})$, and a $0.03 \mathrm{M}$ solution in $\mathrm{C}_{6} \mathrm{D}_{6}(\mathbf{4 C})$. About $0.5 \mathrm{~mL}$ of each independently prepared solution of 4 was transferred into a pre-cooled XAS cup, covered with Mylar tape, and frozen in the liquid- $\mathrm{N}_{2}$-cooled cold well of the anaerobic box. Complex $\mathbf{5}$ was prepared by the addition of a thawing THF solution of $\left[\mathrm{PhBP} \mathrm{CH}^{2} \mathrm{Cy}_{3}\right] \mathrm{FeCl}$ to a frozen solution of $\mathrm{Li}(\mathrm{dbabh})$ in $\mathrm{THF}\left(\mathrm{ca} .-110^{\circ} \mathrm{C}\right.$ ) to give a final concentration of $35 \mathrm{mM}$. A stir bar was added to the frozen mixture, which was then allowed to warm to $-50{ }^{\circ} \mathrm{C}$, and stirred for $4 \mathrm{~h}$. The XAS sample was prepared as for 4 . A duplicate sample in THF- $d_{8}$ was analyzed by ${ }^{31} \mathrm{P}$ and ${ }^{1} \mathrm{H}$ NMR spectroscopies at $-50{ }^{\circ} \mathrm{C}$ to ensure clean and quantitative conversion of $\left[\mathrm{PhBP}^{\mathrm{CH} 2 \mathrm{Cy}}{ }_{3}\right] \mathrm{FeCl}$ to 5 .

\section{X-ray Absorption Spectroscopy}

Fe K-edge X-ray absorption spectra were recorded on beamline 9-3 of the Stanford Synchrotron Radiation Laboratory (SSRL), Stanford Linear Accelerator Center (storage ring conditions, 3 $\mathrm{GeV}, 50-100 \mathrm{~mA}$ ), and on beamline X9B of the National Synchrotron Light Source (NSLS), Brookhaven National Laboratory (storage ring conditions, $2.8 \mathrm{GeV}, 100-300 \mathrm{~mA}$ ). The samples were maintained at a constant temperature between 5 and $15 \mathrm{~K}$ during data collection over the energy range $6.9-8.0 \mathrm{keV}$ ( $\mathrm{Si}(220)$ double-crystal monochromator). Contamination of higher harmonics radiation was minimized by using a bent focusing mirror (beamline 9-3 at SSRL) or by a harmonic rejection mirror (beamline X9B at NSLS). To reduce the flux intensity at beamline 9-3, the defocused beam was attenuated by Al foil. Spectra were measured with $10 \mathrm{eV}$ steps below the edge, $0.3 \mathrm{eV}$ steps in the edge region, and steps equivalent to 0.05 $\AA^{-1}$ increments above the edge (region borders were 6880,7090 , and $7140 \mathrm{eV}$ at beamline 9-3, SSRL, and 6932, 7102, and $7137 \mathrm{eV}$ at beamline X9B, NSLS). An iron foil spectrum was recorded concomitantly for internal energy calibration and the first inflection point of the K- 
edge energy was assigned to $7112.0 \mathrm{eV}$. The data were obtained as fluorescence excitation spectra $\left(A_{\exp }\left(C_{\mathrm{f}} / C_{0}\right)\right)$ using a solid state Ge detector (Canberra).

The iron concentration in the samples and the number of scans acquired for each sample were as follows: 1,0.2 M Fe, 3 scans (30 detector elements, SSRL); 2,0.16 M Fe, 3 scans (30 detector elements, SSRL); 3,0.16 M Fe, 3 scans (30 detector elements, SSRL); 4A, $0.01 \mathrm{M} \mathrm{Fe}$ in benzene- $d_{6}, 10$ scans ( 27 detector elements, SSRL); 4B, $0.03 \mathrm{M} \mathrm{Fe}$ in toluene- $d_{8}, 10$ scans (30 detector elements, SSRL); 4C, $0.03 \mathrm{M} \mathrm{Fe}$ in benzene- $d_{6}, 6$ scans (12 detector elements, NSLS); 5, $0.035 \mathrm{M}$ Fe in THF, 4 scans (28 detector elements, SSRL).

The data analysis was carried out using the programs EXAFSPAK ${ }^{19}$ and SSExafs $^{20}$ as described. ${ }^{21-23}$ EXAFS data for $\mathbf{1} \mathbf{- 4}$ are shown in the Supporting Information (Figure S1). Curve-fitting of XANES data to obtain pre-edge peak areas: The edge was modeled as an integral of a $75 \%$ Gaussian and $25 \%$ Lorentzian peak. The heights, positions and widths (at half height) of pre-edge peaks were refined using a Gaussian function. Refinements with multiple peaks were constrained to have a common width for all peaks. Peak energies and intensities are listed in Table S1.

\section{Density Functional Theory (DFT) Computations}

Molecular geometries of $\left[\mathrm{PhBP}^{i \mathrm{Pr}}{ }_{3}\right] \mathrm{Fe}^{\mathrm{III}} \equiv \mathrm{N}^{t} \mathrm{Bu}$ (which we use here as a truncated model of 3) and $\left[\mathrm{PhBP}^{i P r}{ }_{3}\right] \mathrm{Fe}^{\mathrm{IV}} \equiv \mathrm{N}(4)$ had been previously obtained using DFT energy minimization methods. ${ }^{13,17}$ Using these optimized geometries, single-point DFT computations were performed with the Amsterdam Density Functional (ADF) 2003.01 software package. ${ }^{24-26}$ These computations were carried out on a cluster consisting of Intel Xeon processors (Ace Computers) using an uncontracted triple- $\zeta$ Slater-type orbital including a single set of polarization functions as a basis set (ADF basis set IV), an integration constant of 4.0, and the local density approximation of Vosko, Wilk, and Nusair, ${ }^{27}$ with the nonlocal gradient corrections of Becke ${ }^{28}$ and Perdew. ${ }^{29}$ Core orbitals were frozen through $1 \mathrm{~s}(\mathrm{O}, \mathrm{N}, \mathrm{B})$ and $2 \mathrm{p}$ $(\mathrm{Fe}$ and $\mathrm{P})$. Calculations for $\left[\mathrm{PhBP}^{i \mathrm{Pr}}{ }_{3}\right] \mathrm{Fe} e^{\mathrm{III}} \equiv \mathrm{N}^{t} \mathrm{Bu}$ and $\left[\mathrm{PhBP}^{i{ }^{i P r}}{ }_{3}\right] \mathrm{Fe}^{\mathrm{IV}} \equiv \mathrm{N}$ were converged to the $S=1 / 2$ and $S=0$ spin states. Because we performed these computations to gain insights into the factors contributing to the pre-edge areas of $\mathbf{3}$ and $\mathbf{4}$, we performed additional single-point calculations to model the $1 \mathrm{~s} \rightarrow 3 \mathrm{~d}_{\mathrm{z}^{2}}$ excited state, following the method of Westre et al. 30 in order to assess what effect this electronic transition has on the $\mathrm{Fe} 3 \mathrm{~d} \mathrm{MO}$ compositions. For these computations, the 1 s hole was approximated by substituting $\mathrm{Co},(Z+1$ relative to $\mathrm{Fe})$ for $\mathrm{Fe}$, and a $3 \mathrm{~d}^{n+1}$ electronic configuration was used to add an additional electron to the $3 \mathrm{~d}$ manifold. These $1 \mathrm{~s} \rightarrow 3 \mathrm{~d}_{\mathrm{z}} 2$ excited state calculations yielded $\mathrm{Fe} 3 \mathrm{~d}$ MO compositions virtually identical to those computed for the ground states of $\mathbf{3}$ and $\mathbf{4}$ (changes in contribution of $\sim 1 \%$ were observed), and thus, for these complexes, it appears reasonable to use the ground-state MO compositions to gain insight into $1 \mathrm{~s} \rightarrow 3 \mathrm{~d}$ transition intensities.

\section{Results and Discussion}

Fe K-edge X-ray absorption spectra were obtained for $\mathbf{1}, \mathbf{2}$, and $\mathbf{3}$ as solid BN samples and for $\mathbf{4}$ and 5 in frozen solution. The methods by which $\mathbf{1 - 5}$ can be generated are shown in Scheme 1. While 1, 2, and $\mathbf{3}$ could be isolated in pure form, samples of $\mathbf{4}$ and $\mathbf{5}$ were prepared in situ by decay of respective $2^{\prime}$ precursors at ambient temperature and $-50{ }^{\circ} \mathrm{C}$, respectively, and then frozen. Because $\mathbf{4}$ itself was thermally unstable via its bimolecular decay to $\mathbf{1}$, a high purity sample was difficult to obtain at the high concentrations used for our X-ray absorption spectroscopic measurements. Indeed a recently reported Mössbauer study showed that a frozen $0.04 \mathrm{M}$ sample of $\mathbf{4}$ consisted of a mixture of components, a 35-\% fraction corresponding to the nitridoiron(IV) species and a $65-\%$ fraction representing three lower valent species, including $1 .{ }^{17}$ For our XAS studies, three samples of $\mathbf{4}(\mathbf{4 A}, \mathbf{4 B}$, and $4 \mathrm{C})$ were independently prepared and analyzed, and a Mössbauer analysis of $\mathbf{4 C}$ revealed that the nitridoiron(IV) 
complex represented $50 \%$ of the sample. On the other hand, 5 was stable at $-50{ }^{\circ} \mathrm{C}$ and did not undergo bimolecular decay.

Fe K-edge X-ray absorption spectra are shown in Figure 1. Complexes $\mathbf{1}-\mathbf{5}$ exhibit distinct features in the pre-edge region. The total pre-edge peak intensities for $\mathbf{1}, \mathbf{2}$, and $\mathbf{3}$ range from 16 to 25 units (Table 1) and compare well to values observed for other tetrahedral iron complexes. ${ }^{30}$ These pre-edge peaks can be attributed to $1 \mathrm{~s}$-to-3d transitions, which are electric quadrupole allowed and can further gain intensity in tetrahedral iron environments from the electric-dipole mechanism due to mixing of $3 \mathrm{~d}$ and $4 \mathrm{p}$ orbitals. Strikingly more intense are the pre-edge features associated with samples of $\mathbf{4}$ and 5. Samples of $\mathbf{4}$ have peak areas of 60-70 units for the three preparations studied. Considering that our samples of $\mathbf{4}$ consist of approximately equal fractions of $\mathbf{4}$ and of lower valent complexes, which we assume to have an average peak area of 20 units, we can estimate that 4 has an intrinsic peak area of $~ 100(20)$ units. In excellent corroboration of this estimate, the much purer sample of 5 exhibits a preedge peak area of 92 units. For comparison, the two related six-coordinate nitridoiron complexes reported by Wieghardt, $\left[\mathrm{Fe}^{\mathrm{V}}\right.$ (cyclam-acetato $\left.)(\mathrm{N})\right]^{+}$and $\left[\mathrm{Fe}^{\mathrm{VI}}\left(\mathrm{Me}_{3}\right.\right.$ cyclam-acetato) $(\mathrm{N})]^{2+}$ (cyclam-acetate anion=1-carboxymethyl-1,4,8,11-tetraazacyclotetradecane; $\mathrm{Me}_{3}$ cyclam-acetate anion = 1-carboxymethyl-4,8,11-trimethyl-1,4,8,11-

tetraazacyclotetradecane) have pre-edge intensities of 27 and 39 units, respectively. ${ }^{14,} 15 \mathrm{~A}$ recently reported oxoiron(V) complex has also been found to have a pre-edge peak area of approximately 60 units. ${ }^{31}$ Thus, the pre-edge peak areas associated with tetrahedral nitridoiron (IV) complexes $\mathbf{4}$ and $\mathbf{5}$ are the largest reported to date for a high-valent iron complex.

The pre-edge peak energies of complexes $\mathbf{1}-\mathbf{3}$ are essentially identical at 7112.5(1) eV (reported as centroids, Table 1), despite the fact that these complexes span three formal oxidation states. This might seem surprising, because the $1 \mathrm{~s} \rightarrow 3 \mathrm{~d}$ transition energies typically increase with the oxidation state of the metal. For $\mathbf{1 - 3}$, we speculate that there is electronic modulation of the electron density at the iron center as a function of the $\mathrm{N}_{\mathrm{x}}$ ligand occupying the fourth site. This idea is consistent with a recent Mössbauer study that established remarkably similar isomer shifts for the iron(I) complex 1 and the iron(II) complexes $\left[\mathrm{PhBP}^{i \mathrm{Pr}}{ }_{3}\right] \mathrm{FeCl}$ and $\mathbf{2}^{\prime} .{ }^{17} \mathrm{Several}$ factors are likely at play. For example, the $\pi$-acidic dinitrogen ligand of 1 to an extent withdraws electron density from the iron(I) center. The phosphine ligands may exert similar effects. ${ }^{17}$ By contrast, the $\pi$-basic imido ligand of 3 donates $\pi$ electron density to the formally iron(III) center, in this case compensating for the expected decrease in the electron density at the metal in a higher formal oxidation state.

Complex 5 exhibits a pre-edge peak energy at $7113.1 \mathrm{eV}$, upshifted only $0.6 \mathrm{eV}$ relative to those of $\mathbf{1}-\mathbf{3}$ and consistent with the metal-ligand covalency arguments in the previous paragraph. Samples of $\mathbf{4}$ also show similar values, with an average of 7113.0(1) eV. Although samples of $\mathbf{4}$ contain a mixture of the nitridoiron(IV) complex and other lower valent species, the contribution of the former dominates due to its much higher intensity. The pre-edge peak energies of $\mathbf{4}$ and $\mathbf{5}$ do not appear too unusual when compared with values of other high-valent FeN complexes. They are ca. $0.8 \mathrm{eV}$ lower than that found for an imidoiron(IV) complex $(7113.9 \mathrm{eV}){ }^{23}$ and $2 \mathrm{eV}$ lower than that found for an nitridoiron(V) complex $(7115.0 \mathrm{eV})$. 1432

Metal-ligand distances can be extracted from the EXAFS region of the X-ray absorption spectra. We have used the crystallographically characterized compounds $\mathbf{1}, \mathbf{2}$ and $\mathbf{3}$ to calibrate our EXAFS analysis of the $\left[\mathrm{PhBP}^{i \mathrm{Pr}}{ }_{3}\right] \mathrm{FeN}$ complex described here. The Fourier transforms of the Fe K-edge EXAFS data for these complexes each display a prominent feature centered at $r^{\prime}$ near $2 \AA$ (non-phase-shift-corrected, Figure $2 \mathrm{~A}$ ) that can be attributed to the three phosphorus scatterers of the $\left[\mathrm{PhBP}^{i \mathrm{Pr}_{3}}\right]$ ligand. There is a progressive decrease in these values in the order $\mathbf{2}, \mathbf{1}$ and $\mathbf{3}$ that corresponds the shortening of the Fe-P bond lengths ( $\left.r_{\mathrm{Fe}-\mathrm{P}}\right)$ from 2.46 to 2.27 
$\AA$ A between high spin $2(S=2)$ to low $\operatorname{spin}(S=1 / 2) 3$. A second shorter shell can be introduced in these fits that can be associated with the $\mathrm{N}$ scatterer in each of these complexes. The Fe-P and $\mathrm{Fe}-\mathrm{N}$ distances obtained from fits to the EXAFS spectra match the crystallographically determined distances well (Table 1). In addition, there is a broad feature at $r^{\prime}$ near $4.4 \AA$ in the spectrum of $\mathbf{1}$ (and not observed in the other two complexes) that likely arises from the other $\mathrm{Fe}$ center of the linear $\mathrm{Fe}-\mathrm{N}-\mathrm{N}-\mathrm{Fe}$ unit, consistent with the $\mathrm{Fe} \cdots \mathrm{Fe}$ distance of $4.75 \AA$ determined by X-ray crystallography. 13

Since diffraction quality crystals are not yet available for the nitridoiron(IV) complexes $\mathbf{4}$ and 5, the analysis of their EXAFS data provides an alternative for obtaining information on the iron-ligand bond lengths. The EXAFS analysis for $\mathbf{5}$ is presented first, as it is more straightforward to analyze. Complex $\mathbf{5}$ does not suffer the complications encountered in frozen high-concentration samples of $\mathbf{4}$ where dimerization of $\mathbf{4}$ to $\mathbf{1}$ occurs, resulting in a mixture of species. ${ }^{17}$ The Fourier-transformed EXAFS spectrum of 5, shown in Figure 2C, shows two principal features at $r^{\prime}=1.4$ and $1.9 \AA$ that can be associated with the first coordination sphere scatterers. The more intense peak at $r^{\prime}=1.9 \AA$ corresponds to the P scatterers of the tridentate supporting ligand with $r_{\mathrm{Fe}-\mathrm{P}}=2.19(2) \AA$, while the smaller peak at $r^{\prime}=1.4 \AA$ corresponds to an N scatterer at 1.55(2) A. The latter is associated with a Debye-Waller factor that is larger than might be expected for a short $\mathrm{Fe}-\mathrm{X}$ bond, but such values have also been reported by Wieghardt and co-workers in the analysis of their nitridoiron(V) and nitridoiron(VI) complexes. ${ }^{14,} 15$ It may also be noted that the introduction of the $\mathrm{N}$ scatterer does not result in a large improvement in the goodness-of-fit (GOF) factor (compare fits $2 \mathrm{~d}$ vs $4 \mathrm{~d}$ in Table 2). We attribute this to the much greater scattering power of the P scatterers, which dominates the EXAFS spectrum. In support, fits $5 \mathrm{~d}$ and $6 \mathrm{~d}$ in Table 2 show the results of fitting $\chi k$-weighted data (instead of the usual $\chi k^{3}$-weighted data) where the introduction of the $\mathrm{N}$ scatterer does exhibit a $30 \%$ decrease in the GOF factor.

The EXAFS analysis of samples $\mathbf{4 A - C}$ is consistent with that for $\mathbf{5}$ (Figures $2 \mathrm{~B}$ and S5). There are three prominent features observed, centered at $r^{\prime} \approx 1.4,1.8$, and $2.1 \AA$. The features at $r^{\prime}=$ 1.8 and $2.1 \AA$ correspond to P scatterers with $r_{\mathrm{Fe}-\mathrm{P}}=2.22(2)$ and $2.44(2) \AA$, which we assign to two different $\left[\mathrm{PhBP}^{i \mathrm{Pr}}{ }_{3}\right] \mathrm{Fe}$ species. Fits with systematically varied coordination numbers for the two shells were evaluated, with the total number of $P$ scatterers fixed at 3 . The fit with equal fractions for the two components $(n=1.5)$ gave the most reasonable Debye-Waller factors for each subshell and a substantial decrease in the goodness-of-fit (GOF) value as compared to a single-shell fit (Table S4). These results are consistent with the Mössbauer analysis and suggest that the high-concentration samples of $\mathbf{4}$ studied here can be divided into approximately equal amounts of a high-valent fraction with P scatterers at 2.22(2) $\AA$, similar to those found in 5, and a lower-valent fraction with P scatterers at 2.44(2) $\AA$, like those found in $\mathbf{2}$.

The third feature in the EXAFS spectra of $\mathbf{4}$ is a peak at $r^{\prime} \approx 1.4 \AA$, which is fit by an N scatterer at $1.52(2) \AA$ with a coordination number of 0.5 . Because this distance agrees with the $\mathrm{Fe}-\mathrm{N}$ distance in $\mathbf{5}$, this scatterer is assigned to the nitrido of the high-valent fraction of $\mathbf{4}$. The fits to the data further improve with the inclusion of a $\mathrm{N}$ scatterer with a coordination number of 0.5 at $1.82 \AA$ for $\mathbf{4 B}$ or at $\sim 2.0 \AA$ for $\mathbf{4 A}$ and $\mathbf{4 C}$, which respectively correspond to the $\mathrm{N}$ scatterers of $\mathbf{1}$ and $\mathbf{2}$. While a further decrease in the GOF value could be obtained by splitting the latter shell into two subshells representing both distances (fits 5a,b,c, Table 2), the fits resulted in subshells with unreasonably negative Debye-Waller factors (Tables S4 and S5). We surmise that the lower valent fraction in samples of $\mathbf{4}$ consists of a mixture of $\mathbf{1}$ and $\mathbf{2}$. Additional evidence for the presence of $\mathbf{1}$ in the samples of $\mathbf{4}$ is the appearance of a feature at $r^{\prime} \approx 4.4 \AA$ observed only in the spectrum of $\mathbf{1}$ in this series of complexes that is associated with the $\mathrm{Fe}$ scatterer of a linear $\mathrm{Fe}-\mathrm{N}-\mathrm{N}-\mathrm{Fe}$ unit. This feature is somewhat more prominent in the $30-\mathrm{mM}$ sample 4B than in the 10-mM sample 4A (compare Figures 2B and S5 bottom), consistent with the expected concentration dependence for the dimerization of $\mathbf{4}$ to form $\mathbf{1}$. 
The Fe-N distances ranging from 1.51-1.55 $\AA$ obtained in the fits for $\mathbf{4}$ and $\mathbf{5}$ (Table 2) agree with the value of $1.51 \AA$ predicted by DFT calculations. ${ }^{13,} 17$ This distance is even shorter than the 1.57 and $1.61 \AA \mathrm{Fe}-\mathrm{N}$ distances respectively found for the higher-valent six-coordinate nitridoiron(VI) and -iron(V) complexes of the $\mathrm{R}_{3}$ cyclam-acetato ligands. ${ }^{14,15} \mathrm{In}$ the series of $\left[\mathrm{PhBP}^{i{ }^{i r}}{ }_{3}\right] \mathrm{Fe}$ complexes probed here, we note the progressive shortening of (i) the $\mathrm{Fe}-\mathrm{P}$

distances from $2.46 \AA$ for $\mathbf{2}$ to $2.27 \AA$ for $\mathbf{3}$ to $2.2 \AA$ for $\mathbf{4}$ and $\mathbf{5}$ and (ii) the corresponding $\mathrm{Fe}-$ $\mathrm{N}$ distances from 1.953 to 1.638 to $1.53 \AA$, respectively. The major contraction in both $\mathrm{Fe}-\mathrm{P}$ and $\mathrm{Fe}-\mathrm{N}$ distances (from 2 to 3 ) predominantly reflects a change from a high spin to a low spin electronic configuration, while the substantial contraction in the $\mathrm{Fe}-\mathrm{N}$ distance from $\mathbf{3}$ to $\mathbf{4}$ and $\mathbf{5}$ reflects the expected rehybridization that occurs at nitrogen upon transitioning from a substituted imide to a terminal $\mathrm{N}$-atom functionality. ${ }^{13}$

To gain quantitative insight into the geometric and electronic factors that contribute to the preedge intensities of these complexes, we compared the results of DFT computations performed for models of $\mathbf{3}$ and $\mathbf{4}$. An extensive spectroscopic and computational investigation of a series of $\mathrm{Fe}^{\mathrm{II}}$ and $\mathrm{Fe}{ }^{\mathrm{III}}$ coordination compounds with different donor ligands and metal ion geometries by Solomon and co-workers demonstrated that there is a direct correlation between pre-edge intensity and the percentage $\mathrm{Fe} 4 \mathrm{p}$ character mixed into the Fe $3 \mathrm{~d}$-based MOs. ${ }^{30}$ Specifically, it was determined that, for $\mathrm{Fe}^{\mathrm{III}}$ complexes, 1.5 units of pre-edge intensity corresponds to $1 \%$ $4 \mathrm{p}$ mixing in the $3 \mathrm{~d}$ manifold. Our DFT computations performed for 3 revealed that the doubly-

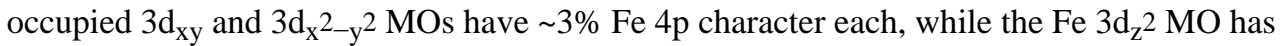
$12 \% 4 \mathrm{p}_{\mathrm{z}}$ character and the $3 \mathrm{~d}_{\mathrm{xz}}$ and $3 \mathrm{~d}_{\mathrm{yz}}$ MOs have less than $1 \% 4 \mathrm{p}$ character (Table 3 ). Assuming that 3 has a $\left(3 d_{x y}\right)^{2}\left(3 d_{x}{ }^{2}-y^{2}\right)^{2}\left(3 d_{z} 2\right) 1$ configuration, a $1 \mathrm{~s} \rightarrow 3 d$ transition can terminate either in the $\mathrm{Fe} 3 \mathrm{~d}_{\mathrm{z}^{2}}$ or $3 \mathrm{~d}_{\mathrm{xz}} / 3 \mathrm{~d}_{\mathrm{yz}}$ MOs, corresponding to ${ }^{2} \mathrm{~A}_{1} \rightarrow{ }^{2} \mathrm{~A}_{1}$ and ${ }^{2} \mathrm{~A}_{1} \rightarrow{ }^{2} \mathrm{E}$ transitions, respectively, assuming $C_{3 \mathrm{v}}$ symmetry. Both of these transitions are electric dipole allowed by group theory, but only the former is expected to have considerable intensity on the basis of the much larger $3 \mathrm{~d} / 4 \mathrm{p}$ mixing in the $3 \mathrm{~d}_{\mathrm{z}} 2$ MO than the $3 \mathrm{~d}_{\mathrm{xz}}$ and $3 \mathrm{~d}_{\mathrm{yz}}$ MOs. In fact, the $12 \% \mathrm{Fe} 4 \mathrm{p}_{\mathrm{z}}$ character in the $3 \mathrm{~d}_{\mathrm{z}}{ }^{2} \mathrm{MO}$ is predicted to give rise to a pre-edge intensity of 18 units, in remarkably good agreement with the experimental observation of 16.2 units (Table 1). Thus, the pre-edge intensity of $\mathbf{3}$ can be well accounted for by the relatively large percentage of $\mathrm{Fe} 4 \mathrm{p}_{\mathrm{z}}$ character in the $3 \mathrm{~d}_{\mathrm{z}} 2 \mathrm{MO}$.

This correlation, however, fails considerably when it is carried on to the $\mathrm{Fe}^{\mathrm{IV}}$ compound 4 . Compound 4 exhibits a pre-edge area roughly seven times that of $\mathbf{3}(\sim 100$ versus 16.2 units, respectively), whereas our DFT computations show that the percentage of $4 \mathrm{p}_{\mathrm{z}}$ mixing into the $3 \mathrm{~d}_{\mathrm{z}} 2 \mathrm{MO}$ of $\mathbf{4}$ is identical to that of $\mathbf{3}$ (i.e., $12 \%$; see Table 3 ). According to the analysis of Westre et al., ${ }^{30}$ the correlation between Fe K-edge pre-edge intensity and $4 \mathrm{p}$ character in the $3 \mathrm{~d}$ manifold is dependent on two factors: i) the oscillator strength of a $1 \mathrm{~s} \rightarrow 4 \mathrm{p}$ transition, which becomes larger with increasing effective nuclear charge on the Fe center and ii) the photoionization cross section for the Fe 1s electron. Consequently, a slightly higher ratio of pre-edge intensity per $\mathrm{Fe} 4 \mathrm{p}$ character is expected for an $\mathrm{Fe}^{\mathrm{IV}}$ center than an $\mathrm{Fe}^{\mathrm{III}}$ center; however this increase cannot account for the remarkably large pre-edge area of $\mathbf{4}$ relative to 3 and other Fe $\mathrm{e}^{\mathrm{III}}$ complexes. While there might be several reasons for this discrepancy, the most likely rationale could be the significantly higher metal-ligand covalency in the $\mathrm{Fe}^{\mathrm{IV}}$ system, which mixes ligand $\mathrm{p}$ character into the $3 \mathrm{~d}$ MOs. For 3 , the $3 \mathrm{~d}_{\mathrm{z}} 2 \mathrm{MO}$ is almost nonbonding, containing just $6.3 \%$ ligand character. In contrast, 4 contains $35.7 \% \mathrm{~N} 2 \mathrm{p}$ character and $8.4 \% \mathrm{P} 3 \mathrm{p}$ character in its corresponding $3 \mathrm{~d}_{\mathrm{z}} 2 \mathrm{MO}$, potentially providing an alternative mechanism for gaining pre-edge intensity. These two MO's are illustrated in Figure 3. PennerHahn and co-workers have similarly argued that the large pre-edge intensities of high-valent $\mathrm{Mn}$ and $\mathrm{Cr}$ complexes with terminal oxo and nitrido ligands derives from metal-ligand covalency. 35,36 Thus, the large pre-edge area of $\mathbf{4}$ could be attributed to the very short, covalent $\mathrm{Fe} \equiv \mathrm{N}$ bond present in this complex. 
To summarize, we have characterized [ $\left.\mathrm{PhBP}_{3}\right] \mathrm{Fe}(\mathrm{N})$ complexes 4 and 5 by X-ray absorption spectroscopy to obtain direct spectroscopic evidence for a very short $\mathrm{Fe}-\mathrm{N}$ distance. The distance of 1.51-1.55 $\AA$ manifests the $\mathrm{Fe}=\mathrm{N}$ triple bond in accord with the observed $\mathrm{FeN}$ vibration for $4\left(v_{\mathrm{FeN}}=1034 \mathrm{~cm}^{-1}\right)^{13}$ and supporting DFT calculations. ${ }^{17}$ This highly covalent bonding interaction results in the appearance of an unusually intense pre-edge peak with an area of 92 units, which is much larger than those of the related tetrahedral complexes with $\mathrm{Fe}^{\mathrm{I}}-\mathrm{N}_{2}-\mathrm{Fe}^{\mathrm{I}}, \mathrm{Fe}^{\mathrm{II}}-\mathrm{NPh}_{2}$, and $\mathrm{Fe}^{\mathrm{III}}=\mathrm{NAd}$ motifs and those of recently described six-coordinate $\mathrm{Fe}^{\mathrm{V}} \equiv \mathrm{N}$ and $\mathrm{Fe}^{\mathrm{VI}} \equiv \mathrm{N}$ complexes. ${ }^{14,}{ }^{15}$ Compared to the oxoiron(IV) unit prevalent in the catalytic cycles of heme and nonheme iron enzymes, ${ }^{1}$ the nitridoiron(IV) unit of $\left[\mathrm{PhBP}^{\mathrm{R}}{ }_{3}\right] \mathrm{Fe}$ $(\mathrm{N})$ has a much shorter iron-to-ligand multiple bond length, as well as higher pre-edge peak intensity, consistent with the $\pi$ basicity of the nitrido ligand being greater than that for the oxo ligand.

\section{Supplementary Material}

Refer to Web version on PubMed Central for supplementary material.

\section{Acknowledgements}

This work was supported by NIH grants GM-33162 (L.Q.) and GM-070757 (J.C.P.) and postdoctoral fellowship FGM075700 (T.A.J.). We are also grateful for a Department of Defense Graduate Fellowship for T.A.B. and a National Science Foundation Pre-doctoral Fellowship for C.T.S. XAS data were collected on beamline 9-3 at the Stanford Synchrotron Radiation Laboratory (SSRL) and beamline X9B at the National Synchrotron Light Source (NSLS). The SSRL Structural Molecular Biology Program is supported by the Department of Energy, Office of Biological and Environmental Research, and by the National Institutes of Health, National Center for Research Resources, Biomedical Technology Program. NSLS is supported by the U.S. Department of Energy, Office of Science, Office of Basic Energy Sciences, under Contract No. DE-AC02-98CH10886. We thank Dr. Matthew J. Latimer at SSRL and Dr. Nebojsa S. Marinkovic at NSLS for their excellent technical support of our synchrotron experiments, Prof. Michael P. Hendrich and Mr. William Gunderson of Carnegie Mellon University for obtaining a Mössbauer spectrum of sample 4C, and Professor Thomas Brunold of the University of Wisconsin-Madison for graciously providing access to his computer cluster.

\section{References}

1. Shan X, Que L Jr. J Inorg Biochem 2006;100:421-433. [PubMed: 16530841]

2. Mehn MP, Peters JC. J Inorg Biochem 2006;100:634-643. [PubMed: 16529818]

3. Costas M, Mehn MP, Jensen MP, Que L Jr. Chem Rev 2004;104:939-986. [PubMed: 14871146]

4. Bollinger JM Jr, Price JC, Hoffart LM, Barr EW, Krebs C. Eur J Inorg Chem 2005:4245-4254.

5. Howard JB, Rees DC. Chem Rev 1996;96:2965-2982. [PubMed: 11848848]

6. Oldenburg PD, Que L Jr. Catalysis Today 2006;117:15-21.

7. Chen K, Costas M, Que L Jr. Dalton Trans 2002:672-679.

8. Bart SC, Lobkovsky E, Bill E, Chirik PJ. J Am Chem Soc 2006;128:5302-5303. [PubMed: 16620076]

9. Brown SD, Peters JC. J Am Chem Soc 2005;127:1913-1923. [PubMed: 15701026]

10. Betley TA, Peters JC. J Am Chem Soc 2003;125:10782-10783. [PubMed: 12952446]

11. Brown SD, Betley TA, Peters JC. J Am Chem Soc 2003;125:322-323. [PubMed: 12517130]

12. Thomas CM, Mankad NP, Peters JC. J Am Chem Soc 2006;128:4956-4957. [PubMed: 16608321]

13. Betley TA, Peters JC. J Am Chem Soc 2004;126:6252-6254. [PubMed: 15149221]

14. Aliaga-Alcalde N, George SD, Mienert B, Bill E, Wieghardt K, Neese F. Angew Chem Int Ed 2005;44:2908-2912.

15. Berry JF, Bill E, Bothe E, George SD, Mienert B, Neese F, Wieghardt K. Science 2006;312:19371941. [PubMed: 16741074]

16. Wagner WD, Nakamoto K. J Am Chem Soc 1989;111:1590-1598.

17. Hendrich MP, Gunderson W, Behan RK, Green MT, Mehn MP, Betley TA, Lu CC, Peters JC. Proc Natl Acad Sci USA 2006;103:17107-17112. [PubMed: 17090681] 
18. Brown SD, Peters JC. J Am Chem Soc 2004;126:4538-4539. [PubMed: 15070370]

19. George, GN.; Pickering, IJ. EXAFSPAK, Stanford Synchrotron Radiation Laboratory. Stanford Linear Accelerator Center; Stanford, California: 2000.

20. Scarrow RC, Trimitsis MG, Buck CP, Grove GN, Cowling RA, Nelson MJ. Biochemistry 1994;33:15023-15035. [PubMed: 7999760]

21. Rohde JU, Torelli S, Shan X, Lim MH, Klinker EJ, Kaizer J, Chen K, Nam W, Que L Jr. J Am Chem Soc 2004;126:16750-16761. [PubMed: 15612713]

22. Rohde JU, Stubna A, Bominaar EL, Münck E, Nam W, Que L Jr. Inorg Chem 2006;45:6435-6445. [PubMed: 16878956]

23. Klinker EJ, Jackson TA, Jensen MP, Stubna A, Juhász G, Bominaar EL, Münck E, Que L Jr. Angew Chem Int Ed 2006;45:7394-7397.

24. te Velde G, Baerends EJ. J Comput Phys 1992;99:84-98.

25. Guerra CF, Snijders JG, te Velde G, Baerends EJ. Theor Chem Acc 1998;99:391-403.

26. ADF2003.01 SCM. Theoretical Chemistry. Vrije Universiteit; Amsterdam, The Netherlands: http://www.scm.com

27. Vosko SH, Wilk L, Nusair M. Can J Phys 1980;58:1200.

28. Becke AD. J Chem Phys 1986;84:4524-4529.

29. Perdew JP. Phys Rev B 1986;33:8822-8824.

30. Westre TE, Kennepohl P, DeWitt JG, Hedman B, Hodgson KO, Solomon EI. J Am Chem Soc 1997;119:6297-6314.

31. Tiago de Oliveira F, Chanda A, Banerjee D, Shan X, Mondal S, Que L Jr, Bominaar EL, Münck E, Collins TJ. Science 2007;315:835-838. [PubMed: 17185561]

32. See footnote $g$ of Table 1.

33. Scott, RA. Physical Methods in Bioinorganic Chemistry. Spectroscopy and Magnetism. Que, L., Jr, editor. University Science Books; Sausalito, CA: 2000. p. 465-503.

34. Scott RA. Methods Enzymol 1985;117:414-459.

35. Weng TC, Hsieh WY, Uffelman ES, Gordon-Wylie SW, Collins TJ, Pecoraro VL, Penner-Hahn JE. J Am Chem Soc 2004;126:8070-8071. [PubMed: 15225020]

36. Penner-Hahn JE, Benfatto M, Hedman B, Takahashi T, Doniach S, Groves JT, Hodgson KO. Inorg Chem 1986;25:2255-2259. 


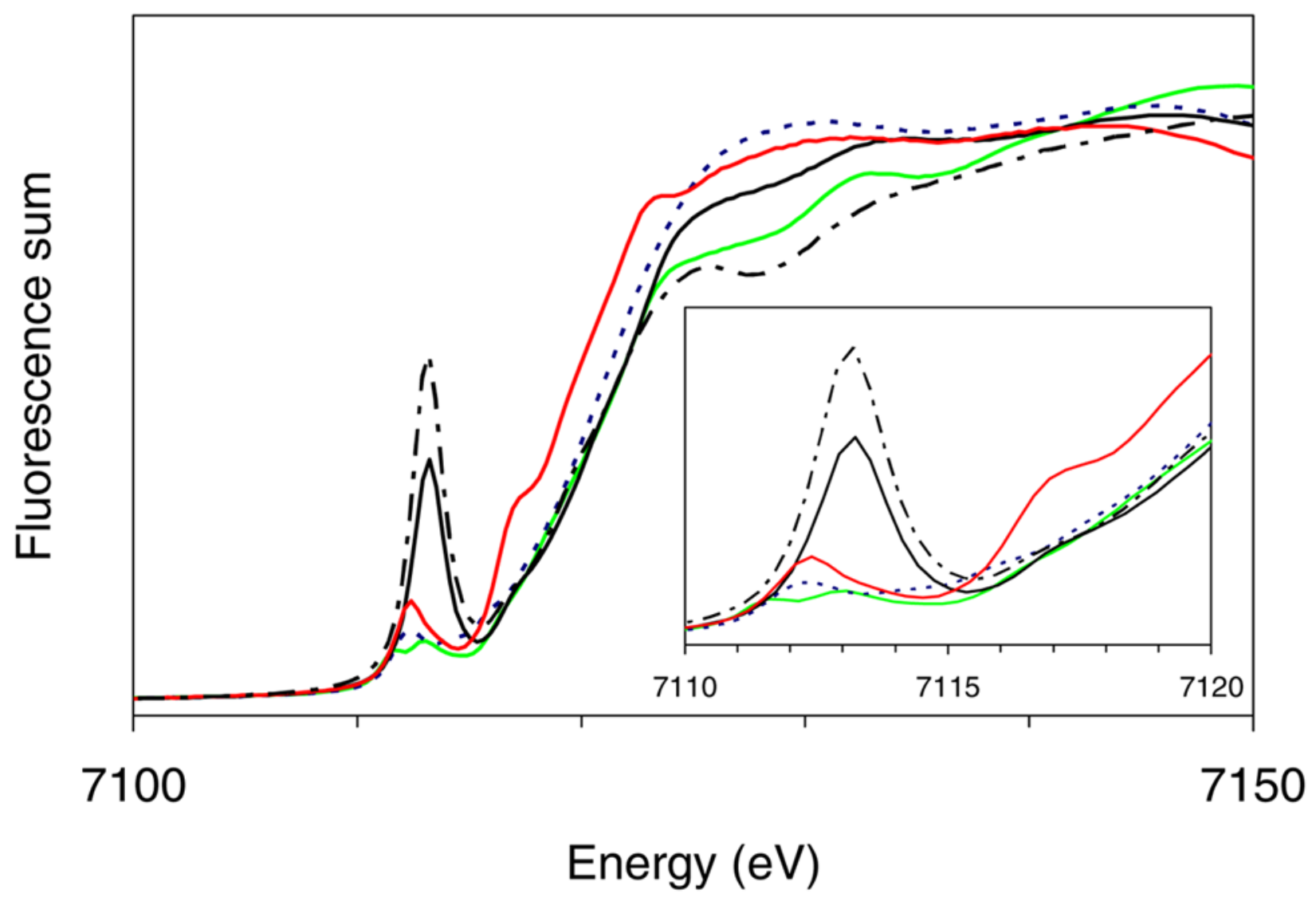

Figure 1.

Fe K-edge X-ray absorption near-edge structures (XANES, fluorescence excitation) of $\left\{\left[\mathrm{PhBP}_{3}{ }^{i \mathrm{Pr}}{ }_{3}\right] \mathrm{Fe}\right\}_{2}\left(\mu-\mathrm{N}_{2}\right), \mathbf{1}(---$, blue $),\left[\mathrm{PhBP}_{3}^{i \mathrm{Pr}_{3}}\right] \mathrm{Fe}\left(\mathrm{NPh}_{2}\right), \mathbf{2}(-, \mathrm{red}),\left[\mathrm{PhBP}^{i \mathrm{Pr}_{3}}\right] \mathrm{Fe}(\mathrm{NAd}), \mathbf{3}$ $\left(-\right.$, green), a sample containing $\left[\mathrm{PhBP}^{i \mathrm{Pr}}{ }_{3}\right] \mathrm{Fe}(\mathrm{N}), \mathbf{4 A}(-$, black $)$ and $\left[\mathrm{PhBP}^{\mathrm{CH} 2 \mathrm{Cy}}{ }_{3}\right] \mathrm{Fe}(\mathrm{N})$, 5 (- - - , black). 

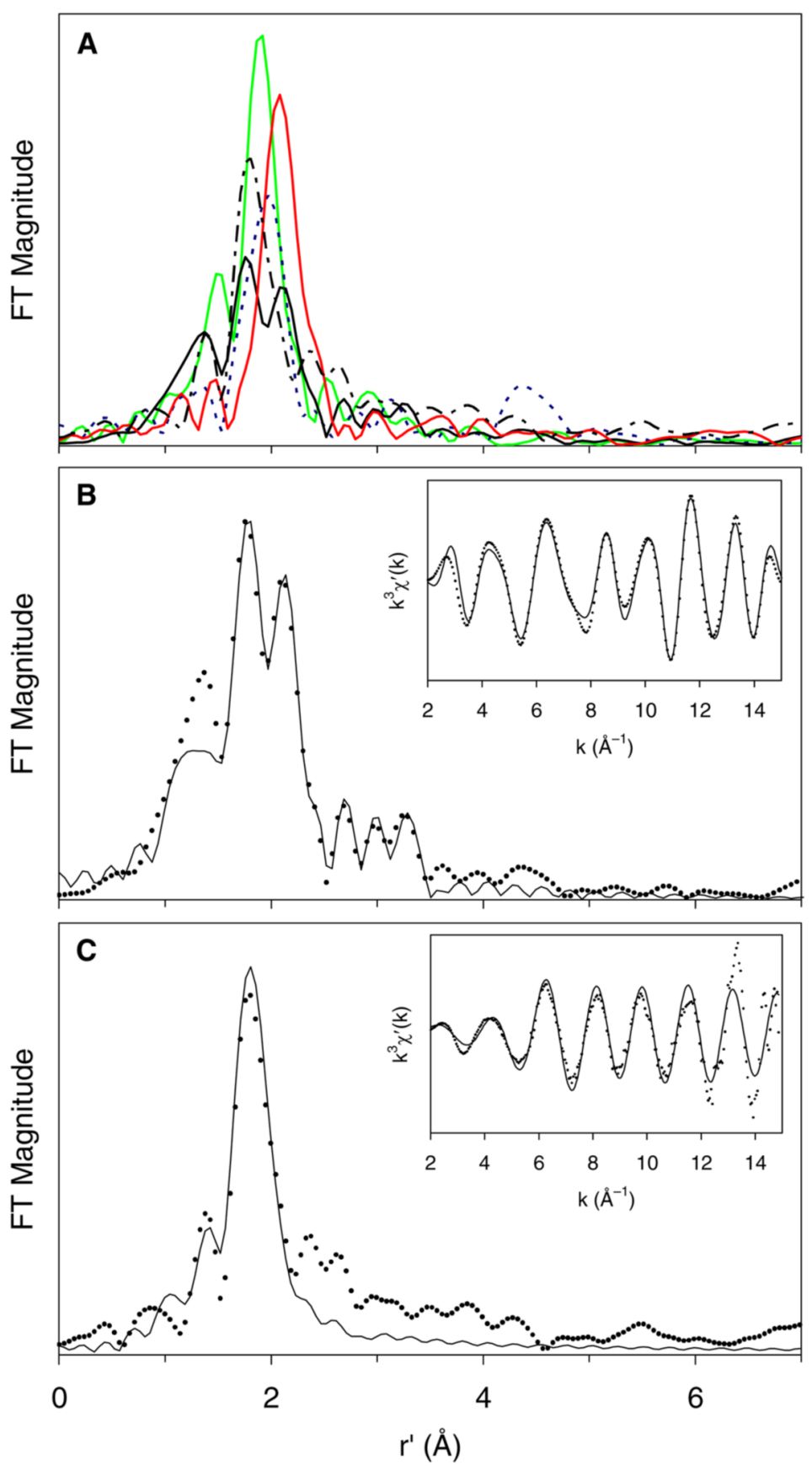

Figure 2.

(A) Fourier transforms of the Fe K-edge EXAFS data $\left(k^{3} \chi(k)\right)$ of $\left\{\left[\mathrm{PhBP}_{3}^{i \mathrm{Pr}_{3}}\right] \mathrm{Fe}\right\}_{2}\left(\mu-\mathrm{N}_{2}\right), \mathbf{1}$ (---, blue), [PhBP $\left.{ }^{i{ }_{3}}{ }_{3}\right] \mathrm{Fe}\left(\mathrm{NPh}_{2}\right), 2$ (一, red), [PhBP ${ }^{i{ }_{3}}{ }_{3} \mathrm{Fe}(\mathrm{NAd}), 3$ (一, green), a sample

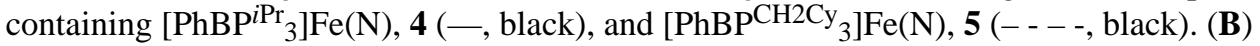
Fourier transform of the Fe K-edge EXAFS data $\left(k^{3} \chi(k)\right)$ and Fourier-filtered EXAFS spectrum $\left(k^{3} \chi^{\prime}(k)\right.$, inset) of $\mathbf{4 A}$ : Fourier-transformed range $k=2-15 \AA^{-1}$; experimental data ( ...) and fit (-); Back-transformation range: $r^{\prime}=0.60-3.80 \AA$. (C) Fourier transform of the Fe K-edge EXAFS data $\left(k^{3} \chi(k)\right)$ and EXAFS spectrum $\left(k^{3} \chi^{\prime}(k)\right.$, inset) of 5: Fourier-transformed range $k$ $=2-15 \AA^{-1}$; experimental data $(\cdots)$ and fit $(-)$; no Fourier-filtering applied. 


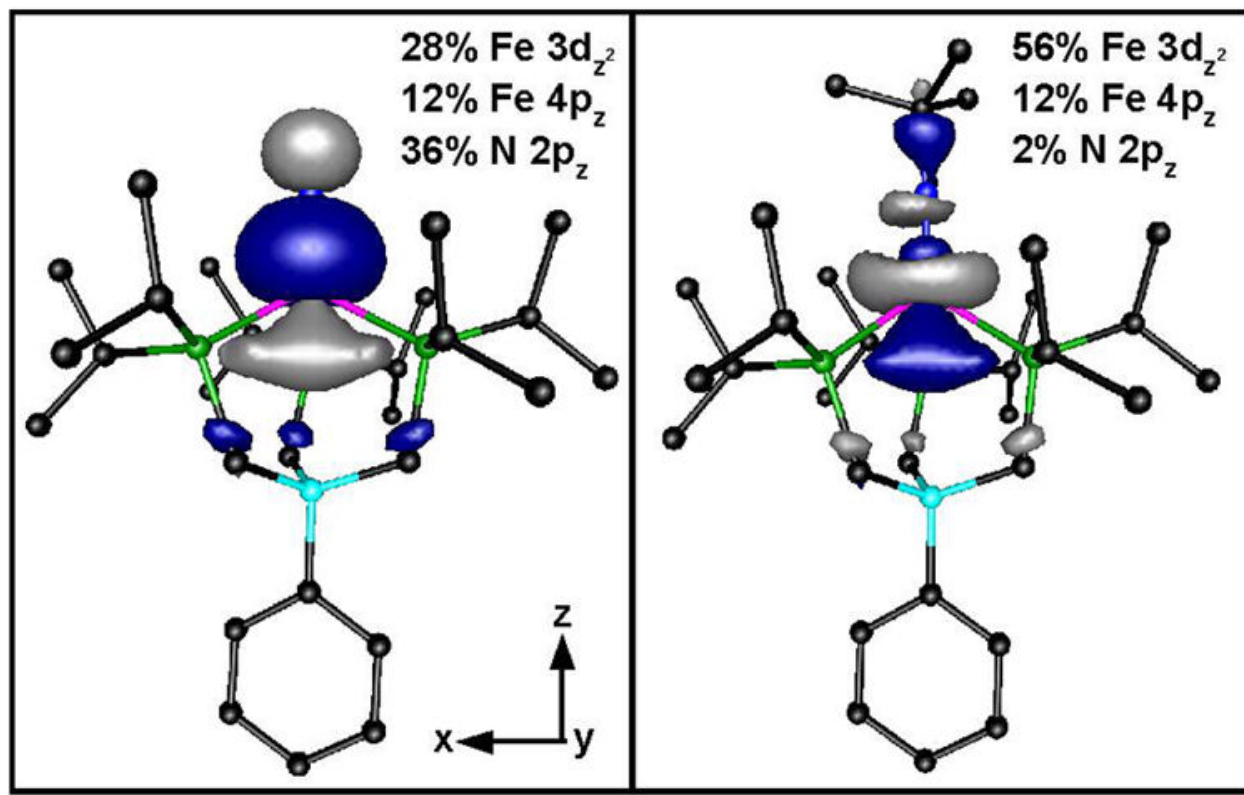

Figure 3.

Contour plots of $\mathrm{Fe} 3 \mathrm{~d}_{\mathrm{z} 2}$-based MOs of $\left[\mathrm{PhBP}^{i \mathrm{Pr}}{ }_{3}\right] \mathrm{Fe}^{\mathrm{IV}}(\mathrm{N})$ (left) and $\left[\mathrm{PhBP}^{i \mathrm{Pr}_{3}}\right] \mathrm{Fe}^{\mathrm{III}}\left(\mathrm{N}^{t} \mathrm{Bu}\right.$ ) (right) based on DFT computations. The contributions to the MOs from the dominant iron, nitrogen, and phosphorus orbitals are listed. 

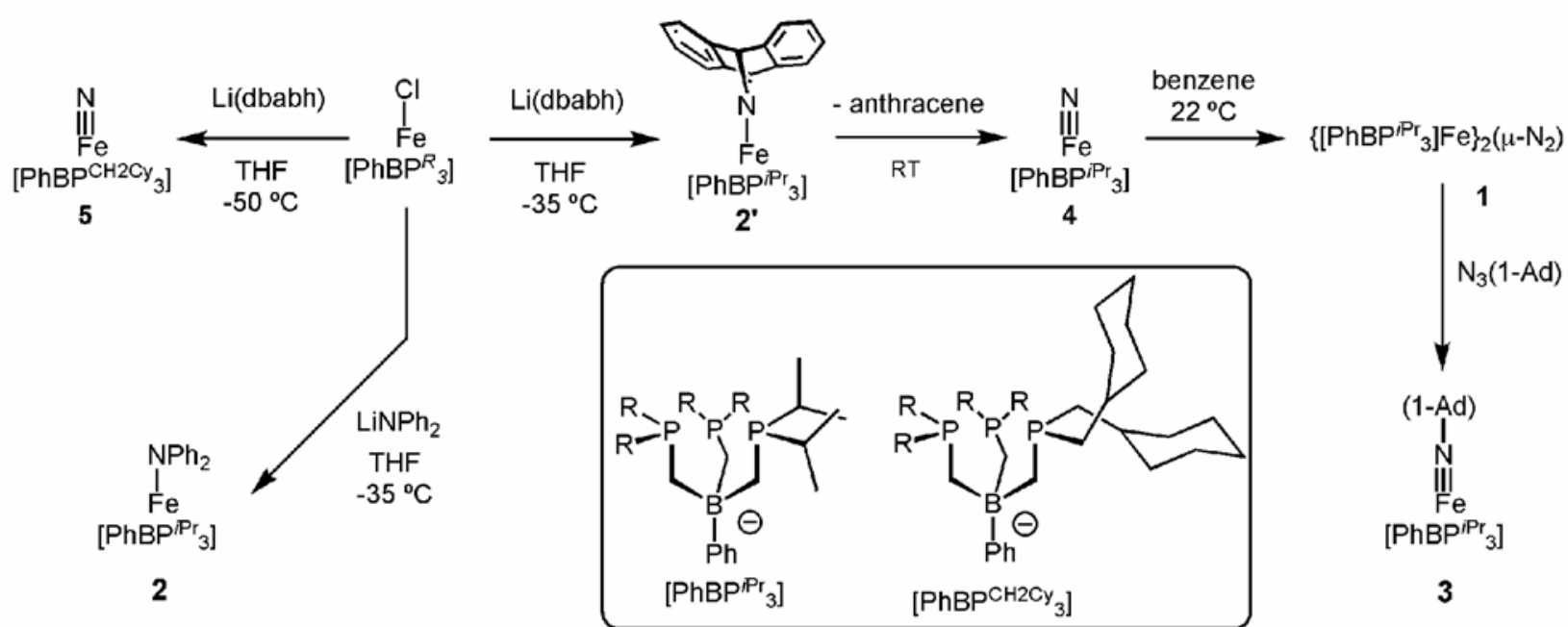

Scheme 1. 
Rohde et al.

Page 13

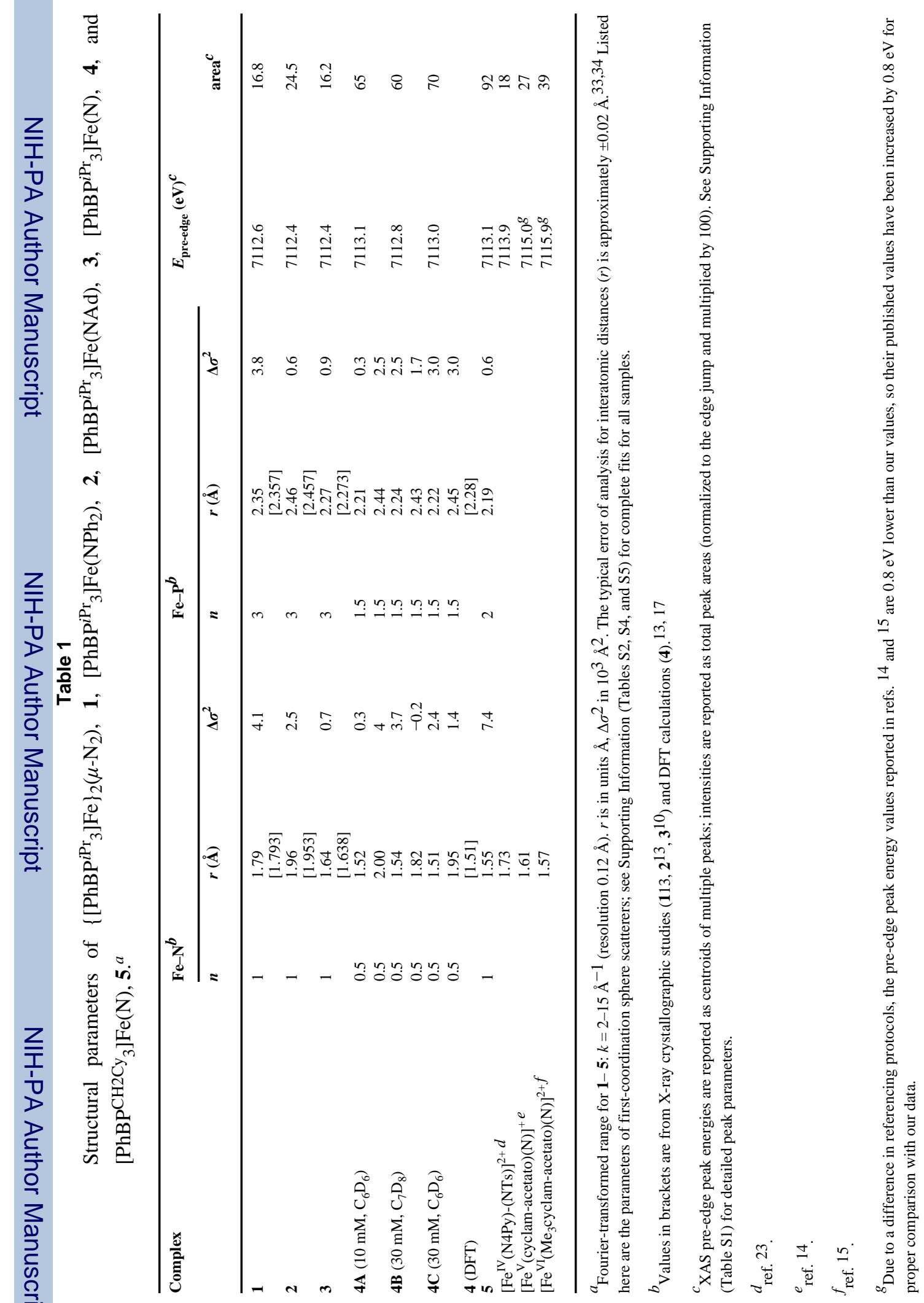

Inorg Chem. Author manuscript; available in PMC 2008 September 12. 


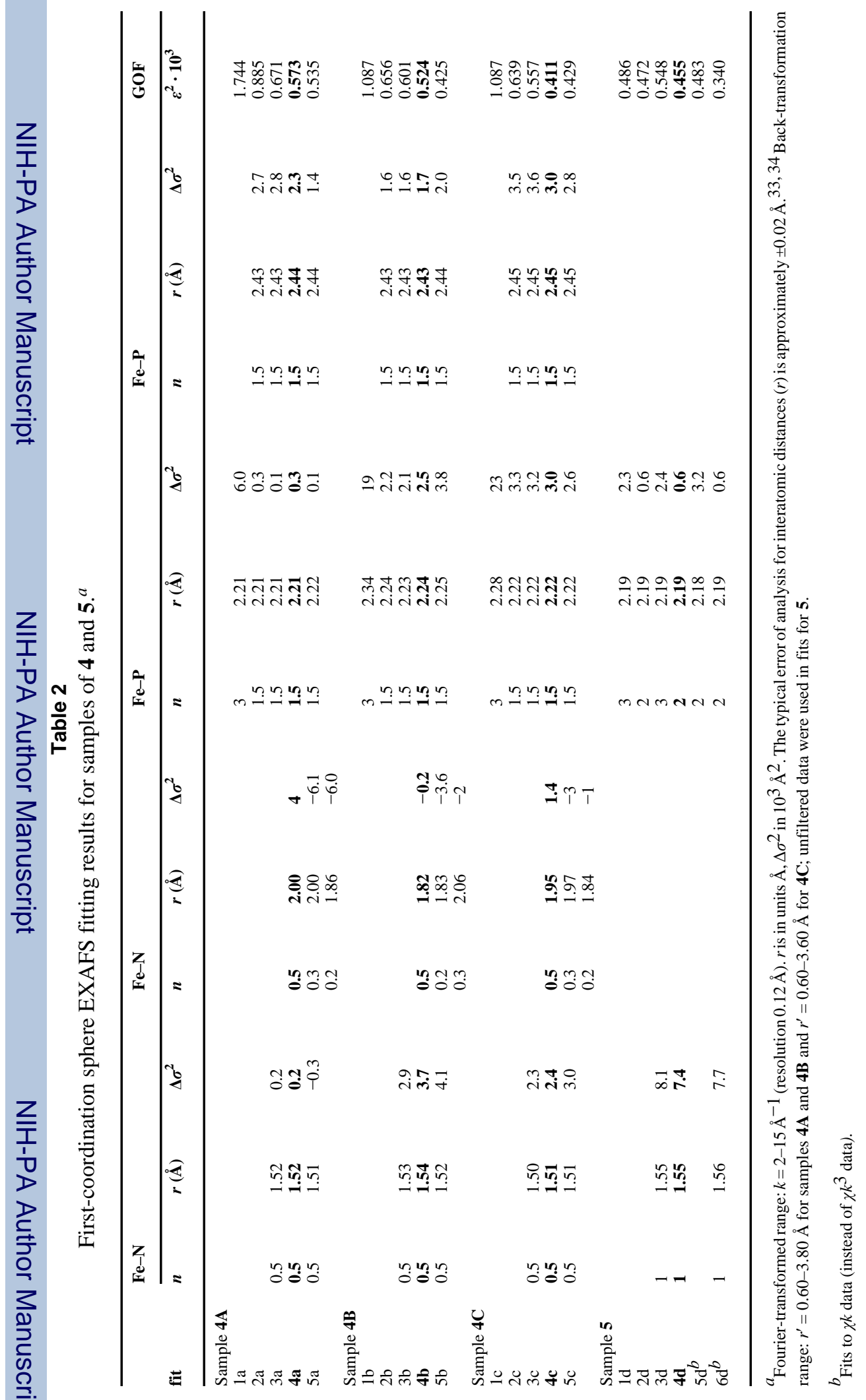

Inorg Chem. Author manuscript; available in PMC 2008 September 12. 


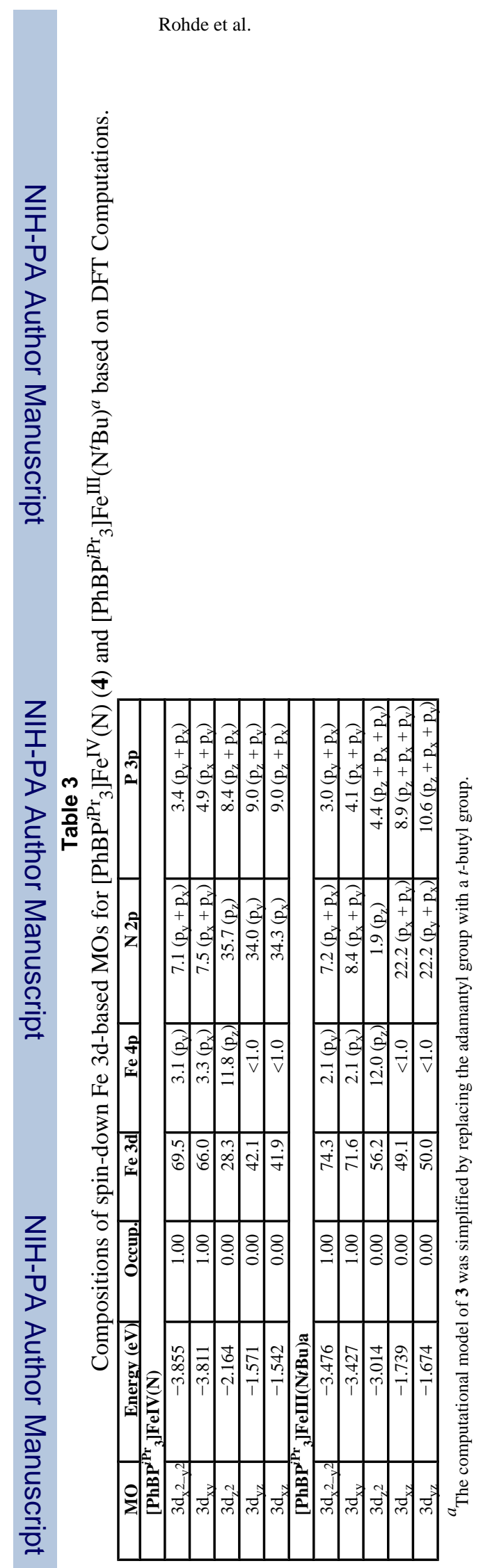

Page 15

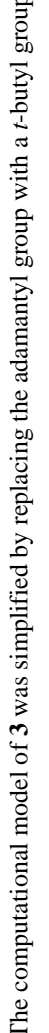

Inorg Chem. Author manuscript; available in PMC 2008 September 12. 